\title{
O Protagonismo Do Poder Judiciário Ante A Necessidade Recorrente Do Controle Judicial De Constitucionalidade De Novas Medidas Provisórias
}

\author{
Angela Soncin* \\ Universidade de Ribeirão Preto, Programa de Pós-Graduação em Direito, Ribeirão Preto-SP, Brasil. \\ (iD https://orcid.org/000o-0002-3994-7985 \\ Juvêncio Borges Silva ** \\ Universidade de Ribeirão Preto, Programa de Pós-Graduação em Direito, Ribeirão Preto-SP, Brasil.
}

Resumo: O presente artigo tem por objetivo destacar que a urgência por marcos regulatórios que disciplinem as situações jamais vivenciadas, como as atualmente geradas pelo estado de calamidade decretado em decorrência do coronavírus (COVID-19), fez com que o Poder Judiciário fosse exaustivamente provocado a se manifestar, o que acabou por gerar discussão acerca do avanço do protagonismo deste Poder ante as medidas adotadas pelo Poder Executivo e Legislativo. A presente pesquisa se justifica uma vez que o Poder Judiciário tem exercido considerável protagonismo na arena social e política, com decisões que têm repercutido sobre estas esferas. Trata-se de uma pesquisa exploratória, qualitativa, que se vale do método analítico-dedutivo, e que se utiliza de livros, artigos científicos e textos doutrinários. Da pesquisa resulta que, apesar do protagonismo do Poder Judiciário, ele não atua de modo a criar um embate entre os Poderes, mas sim que, por meio da existência de diálogos institucionais é possível garantir a prevalência da Constituição Federal sob os interesses políticos, sem interferir na competência dos demais Poderes.

Palavras chave: Marcos regulatórios. Protagonismo. Diálogos Institucionais. Poder Judiciário.

* Mestranda em Direitos Coletivos e Cidadania pela Universidade de Ribeirão Preto - UNAERP. E-mail: bkpacs@hotmail.com

** Pós-doutor em Direito pela Faculdade de Direito da Universidade de Coimbra, Doutor pela Unesp, Mestre pela Unicamp, Graduado em Direito pela Faculdade de Direito de Franca, Graduado em Ciências Sociais pela UEMG, Prof. do Programa de Pós-Graduação em Direitos Coletivos e Cidadania da Universidade de Ribeirão Preto - UNAERP. E-mail: juvencioborges@gmail.com

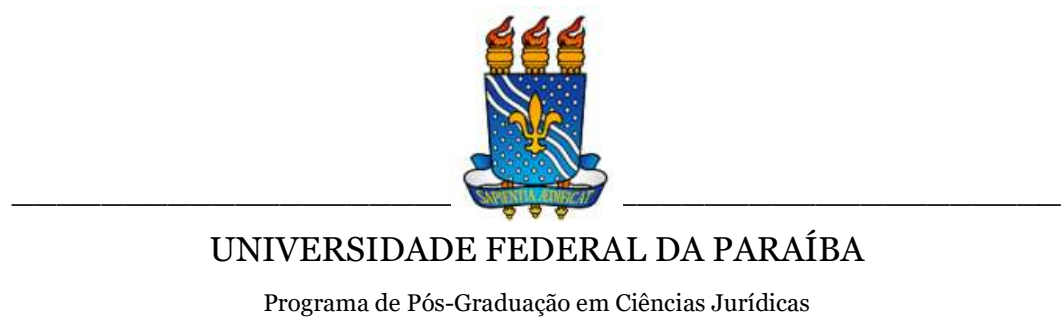

DOI: https://doi.org/ 10.22478/ufpb.1678-2593.2021v20n43.54244 


\title{
O Protagonismo Do Poder Judiciário Ante A Necessidade Recorrente Do Controle Judicial De Constitucionalidade De Novas Medidas Provisórias
}

\author{
Angela Soncin ${ }^{1}$
}

Juvêncio Borges Silva

\section{INTRODUÇÃO}

Antes de adentrarmos propriamente ao tema do presente trabalho, necessário se faz destacar os impactos resultantes da propagação do novo coronavírus (COVID-19), ensejando inúmeras mudanças de hábitos e trazendo instabilidades tanto na área da saúde, como na esfera econômica e jurídica.

Em 30 de janeiro de 2020, a Organização Mundial da Saúde declarou Emergência de Saúde Pública de Importância Internacional, tendo em vista o avanço do novo Coronavírus; sendo em 11 de março de 2020 declarada a existência de uma pandemia (OPAS, 2020).

Diante da situação caótica que o Brasil passava a experimentar, foi por meio do Decreto Legislativo $\mathrm{n}^{\circ}$ 6, de 20 de março de 2020, que o direito positivo reconheceu o estado de calamidade pública e de emergência de saúde pública de importância internacional existente no país.

${ }^{1} \mathrm{O}$ presente trabalho foi realizado com apoio da Coordenação de Aperfeiçoamento de Pessoal de Nível Superior -Brasil (CAPES). 
Assim, no intuito de reduzir o número crescente de mortes $^{2}$, medidas restritivas de circulação foram impostas pelo governo. $\mathrm{O}$ distanciamento social foi recomendado, assim como houve a exigência do fechamento de aeroportos, estabelecimentos comerciais, escolas, clubes, academias, ficando apenas os serviços essenciais em funcionamento.

Mas não foram apenas os hábitos sociais que sofreram alterações, a comunidade jurídica também sentiu os efeitos das mudanças, seja pela ausência de elementos normativos, seja pela urgência na criação de novos marcos regulatórios, ou ainda pela necessidade de adaptação perante os Tribunais, com audiências e plantões virtuais, suspensão de prazos, dentre outras medidas necessárias para manter o distanciamento e ao mesmo tempo o andamento processual.

Foram produzidos por meio do Poder Executivo e do Poder Legislativo, inúmeros e relevantes atos normativos, que variaram desde a regulamentação da relação de trabalho até as relações civis, sendo ainda criadas políticas públicas na tentativa de proteger os sujeitos da economia e trazer, ainda que minimamente, segurança jurídica.

Apesar das medidas emergenciais inicialmente adotadas, o número de mortes ainda é crescente no país e as normas criadas para regulamentar as situações atualmente vivenciadas, apesar de importantes e necessárias, ainda não são suficientes para regular todas as novas necessidades criadas pelo estado de calamidade instaurado.

Além disso, a ausência de precedentes capazes de criar diretrizes lineares para as tomadas de decisões por parte dos Poderes Executivo, Legislativo e Judiciário fez aumentar as controvérsias e, por consequência, a judicialização, sendo, inclusive, discutida a

2“Foram confirmados no mundo 13.616.593 casos de COVID-19 (237.743 novos em relação ao dia anterior) e 585.727 mortes (5.682 novas em relação ao dia anterior) até 17 de julho de 2020" (OPAS, 2020, p. 1). No Brasil, até 18 de julho de 2020 foram registrados 2.046.328 casos (34.177 novos casos em relação ao dia anterior), com um total de 77,851 mortes (WORLD HEALTH ORGANIZATION, 2020). 
constitucionalidade de leis e medidas provisórias criadas neste momento para trazer maior segurança jurídica.

Assim, no que tange diretamente às atividades do Poder Judiciário, ao lado do aumento da judicialização de questões em decorrência do novo cenário experimentado - o que o obriga a realizar a análise das mais variadas matérias - está a necessidade da sociedade por respostas rápidas e eficientes para atender à urgência que o momento requer, sem que, para tanto, o Poder Judiciário tenha parâmetros claros e precedentes concretos para nortear suas decisões.

Dado ao momento vivido, as decisões, seja pela ausência de precedentes, seja pela ausência de parâmetros claros, ou ainda pela necessidade de respostas urgentes, são complexas e podem, por muitas vezes, ser também divergentes, o que não garante o Estado Democrático de Direito e a entrega dos direitos fundamentais.

Neste sentido Veiga e Sivolella (2020, p. 53) trazem que é exatamente sob a ótica das decisões complexas que

\begin{abstract}
[...] reside a preocupação acerca de um elemento norteador a aplanar a ansiedade social e a instabilidade jurídico-normativa que envolvem o peculiar cenário atual. Com efeito, um panorama jurídico de decisões diversas, com soluções dispares e sem um mínimo de critério uniforme, eleva a já crescente insegurança e o temor advindo da falta de isonomia generalizada.
\end{abstract}

O Poder Judiciário, como mencionado anteriormente, acaba por ser, de forma recorrente, chamado para decidir. Instala-se, portanto, uma instabilidade jurídico-normativa e a insegurança jurídica acaba por tomar conta deste cenário, ante a falta de precedentes e de normas capazes de regular as situações singulares vivenciadas neste momento de caos.

Deste modo, atrelado ao aumento da judicialização está o protagonismo do Poder Judiciário, o qual é constantemente provocado, ante a ausência de marcos regulatórios suficientes para garantir a devida e necessária segurança jurídica, para proferir decisões sobre temas ainda não amplamente discutidos e dotados de controvérsias. 
Assim, não há como se negar a necessidade urgente da criação de novos marcos regulatórios capazes de trazer esta segurança e dar a correta aplicabilidade da norma ao caso concreto, sem que para tanto haja a necessidade do protagonismo do Poder Judiciário, seja declarando a constitucionalidade de normas, ou trazendo interpretações para que seja possível realizar a aplicação destas.

Para tanto, o presente trabalho levantará a urgência de marcos regulatórios com destaque ao protagonismo apresentado pelo Poder Judiciário neste momento, assim como tratará acerca da MP 926/2020, da ADI 6341/2020, e ainda sobre o controle de constitucionalidade e a necessidade da realização de diálogos institucionais, que consistem no fato de, ao deliberar, cada poder sopesar as posições e argumentos dos outros Poderes sobre a matéria em análise, e no caso do Poder Judiciário, no exercício do controle de constitucionalidade, ter o cuidado de ouvir de forma compreensiva todas as partes e autoridades envolvidas, tendo em vista a complexidade das questões públicas envolvidas, de forma a intervir quando realmente tal se fizer necessário, nos limites da Constituição Federal.

\section{DA URGÊNCIA DE MARCOS REgULATÓRIOS E O PROTAGONISMO DO PODER JUDICIÁRIO}

Conforme delineado em linhas precedentes, a falta de marcos regulatórios capazes de atender às novas demandas criadas pelo estado de calamidade existente em decorrência do COVID-19 e a ausência de precedentes capazes de criar diretrizes lineares para as tomadas de decisões por parte dos Poderes, acabou por sobrecarregar o Poder Judiciário com o aumento da judicialização, a causar insegurança jurídica com decisões controvertidas sobre matérias semelhantes, assim como passou a exigir do Supremo Tribunal 
Federal manifestações acerca da constitucionalidade de algumas Medidas Provisórias apresentadas pelo Poder Executivo.

Vale aqui destacar, que a judicialização é um fenômeno político, gerado pelas democracias contemporâneas, que é contingencial e tende a se ampliar ou reduzir na medida em que cresce ou diminui a conflituosidade social. É um fenômeno decorrente da ampliação do rol dos direitos sociais, como ocorreu com a Constituição Federal de 1988, da ampliação do acesso à justiça, que acabou por levar ao aumento do número de ações judiciais com vistas à efetivação de direitos sociais, e que também conferiu enorme protagonismo ao Poder Judiciário, na medida em que delegou ao Supremo Tribunal Federal (C.F. art. 102, caput) o status de guardião da Constituição Federal. E considerando o princípio da não denegação da justiça - non liquet -, que obriga o Poder Judiciário a decidir todas as demandas que a ele são submetidas, tal deflagrou o fenômeno que acabou por ser nominado de Judicialização.

Foram muitas as mudanças no sistema jurídico e político, com destaque para o aumento da participação do Estado na sociedade e, diante da inércia dos demais Poderes, abriu-se espaço para a jurisdição dirimir as lacunas deixadas pelos demais "braços" do Estado, sendo o momento pós Segunda Guerra Mundial determinante para a concretização do fenômeno da judicialização da política 3 (Mandarino e Freitas, 2015).

Deste modo, a judicialização, por vezes, pode ser evidenciada como uma técnica compensatória da deficiência dos demais Poderes, o que nos força destacar que a judicialização de questões que deveriam ser solucionadas pelos demais Poderes sobrecarregam o Poder Judiciário, aumentam a litigiosidade e causam insegurança jurídica para a sociedade.

Streck (2011, p. 589) traz que a judicialização é um "fenômeno que exsurge a partir da relação entre os poderes do Estado", do mesmo

3 Neste período, foi possível observar a constitucionalização de direitos, a legitimação dos direitos humanos e as influências dos sistemas norte-americano e europeu. 
modo que Barroso (2012, p. 10) destaca que a judicialização "é um fato, uma circunstância do desenho institucional brasileiro", estando, portanto, diretamente ligada a questões políticas e sociais, não dependendo da vontade do Poder Judiciário.

Como exemplo, podemos citar as Medidas Provisórias no ${ }^{0}$ 926, de 20 de março de 2020 (convertida na Lei 14.035, de 11 de agosto de 2020), $\mathrm{n}^{0}$ 927, de 22 de março de 2020 (atualmente sem validade) e $\mathrm{n}^{\circ} 936$, de $1^{\circ}$ de abril de 2020 (convertida na Lei 14.020, de 6 de julho de 2020), as quais, dentre outras, foram objeto de Ações Direitas de Inconstitucionalidade. Do mesmo modo, podemos citar a tardia publicação da Lei 14.010, de 10 de junho de 2020, resultando em decisões conflitantes sobre o mesmo tema, gerando, por consequência, insegurança jurídica.

A Medida Provisória $n^{0} 926$ propôs alteração na "Lei $n^{0}$ 13.979, de 6 de fevereiro de 2020, para dispor sobre procedimentos para aquisição de bens, serviços e insumos destinados ao enfrentamento da emergência de saúde pública de importância internacional decorrente do coronavírus"(2020), com isso, grande discussão foi travada acerca da competência dos entes federativos para adoção de medidas que envolvam isolamento, quarentena, interdição de locomoção, circulação, além de atividades e serviços essenciais, sendo referida medida objeto da Ação Direta de Inconstitucionalidade 6341, cujo julgamento se deu em 15 de abril de 2020 e será melhor analisado no tópico subsequente.

Já as Medidas Provisórias $n^{0} 927$ e $n^{0}$ 936/2020 foram editadas sob o fundamento de garantir o emprego e a renda do trabalhador e assim evitar demissões em massa e o fechamento de empresas. A Medida Provisória $n^{0} 927$ tratou de medidas trabalhistas para enfrentamento do estado de calamidade pública e da emergência de saúde pública de importância internacional decorrente do coronavírus, enquanto a Medida Provisória 936 instituiu o Programa Emergencial de Manutenção do Emprego e da Renda.

Apesar disso, muitas foram as críticas a estas Medidas Provisórias. A Medida Provisória ${ }^{0} 927$ foi objeto das Ações Direitas 
O Protagonismo Do Poder Judiciário Ante A Necessidade Recorrente Do...

de Inconstitucionalidade 6342 e 6343 e a Medida Provisória nº 936 deu ensejo à Ação Direta de Inconstitucionalidade 6363/2020, todas levantando pontos de inconstitucionalidade trazidos pelas Medidas.

Na decisão proferida na Ação Direita de Inconstitucionalidade 63424, de 26 de março de 2020, fixou-se entendimento de que a Medida Provisória n ${ }^{\circ} 927$ não ultrapassou os limites constitucionais, indeferindo a cautelar pleiteada. Já em decisão proferida em 29 de abril de 2020, negou-se referendo ao indeferimento da medida cautelar tão somente em relação aos artigos 29 e 31 da Medida Provisória $\mathrm{n}^{0}$ 927/20205.

E na Ação Direta de Inconstitucionalidade 6343 foi discutido acerca da alteração trazida ao artigo $3^{\circ}$ da Lei 13.979/2020, reforçando as exigências para restrição de transporte intermunicipal de passageiros, além de estabelecer a necessidade de um ato conjunto dos Ministros de Estado da Saúde, da Justiça e Segurança Pública e da Infraestrutura para dispor sobre a medida, a qual caberia apenas aos

$4 \mathrm{O}$ artigo $2^{\circ}$ da Medida Provisória no 927, de 22 de março de 2020 - e todos os demais preceitos que se diz conflitantes com a Constituição estão nela previstos contém alusão ao estado de calamidade pública decorrente do novo coronavírus e versa que empregado e empregador poderão, buscando a manutenção do vínculo empregatício, estabelecer parâmetros. $\mathrm{O}$ preceito sobrepõe o acordo individual a possíveis instrumentos normativos e remete aos limites revelados na Constituição Federal. A liberdade do prestador dos serviços, especialmente em época de crise, quando a fonte do próprio sustento sofre risco, há de ser preservada, desde que não implique, como consta na cláusula final do artigo, a colocação em segundo plano de garantia constitucional. É certo que o inciso XXVI do artigo $7^{\circ}$ da Constituição Federal, pedagogicamente, versa o reconhecimento das convenções e acordos coletivos de trabalho, quando então se tem, relativamente a convenções, ajuste formalizado por sindicato profissional e econômico e, no tocante a acordo coletivo, participação de sindicato profissional e empresa. O preceito não coloca em segundo plano a vontade do trabalhador. Sugere, isso sim, que o instrumento coletivo há de respeitar, há de ser formalizado em sentido harmônico com os respectivos interesses. Descabe, no que ficou prevista a preponderância do acordo individual escrito, voltado à preservação do liame empregatício - repita-se - ante instrumentos normativos legais e negociais, assentar, no campo da generalidade, a pecha de inconstitucionalidade.” (Sessão realizada por videoconferência)

5"O Tribunal, por maioria, negou referendo ao indeferimento da medida cautelar tão somente em relação aos artigos 29 e 31 da Medida Provisória $n^{0}$ 927/2020 e, nos termos do voto do Ministro Alexandre de Moraes, Redator para o acórdão, suspendeu a eficácia desses artigos, vencidos, em maior extensão, os Ministros Edson Fachin, Roberto Barroso, Rosa Weber e Ricardo Lewandowski, nos termos de seus votos, e os Ministros Marco Aurélio (Relator), Dias Toffoli (Presidente) e Gilmar Mendes, que referendavam integralmente o indeferimento da medida cautelar. Ausente, justificadamente, o Ministro Celso de Mello. Plenário, 29.04.2020" (Sessão realizada inteiramente por videoconferência - Resolução 672/2020/STF). 
Estados. Tendo o Ministro Marco Aurélio de Mello indeferido o pedido cautelar6.

Apesar de toda a discussão envolvendo a Medida Provisória 927, esta vigorou apenas até 19 de julho de 2020, data em que teve sua vigência encerrada, não sendo, portanto, convertida em lei. Com isso, as matérias disciplinadas pela Medida tiveram validade apenas no período de sua vigência, não sendo atualmente aplicadas.

No que tange à Ação Direta de Inconstitucionalidade 6363, houve também pedido cautelar, levantando-se contra a possibilidade trazida pela Medida Provisória ${ }^{0} 936$ de realização de acordos individuais seja para a redução de salário e jornada do trabalhador, seja para a suspensão dos contratos de trabalho, sendo a primeira decisão a tratar do tema proferida em 6 de abril de 2020, pelo Ministro Ricardo Lewandowisk7.

Referida decisão gerou grande insegurança jurídica, uma vez que inovava, o Ministro, com a exigência de que os sindicatos das categorias deveriam ratificar os acordos individuais, até então autorizados pela Medida Provisória, sem a necessidade de qualquer aval por parte dos sindicatos.

Debaixo de muitas críticas, o Supremo Tribunal Federal, quando do julgamento realizado em 17 de abril de 2020, decidiu, por 7 votos a $3^{8}$, por não referendar a medida cautelar proferida pelo

6“As Medidas Provisórias no 926 e 927, no que alteraram preceitos da Lei no 13.979/2020, hão de ser examinadas a partir de cautela maior, abandonando-se o vezo da crítica pela crítica. União, Estados, Distrito Federal e Municípios, dirigentes em geral, devem implementar medidas que se façam necessárias à mitigação das consequências da pandemia verificada, de contornos severos e abrangentes" (2020).

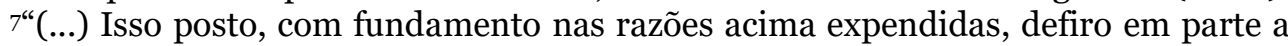
cautelar, ad referendum do Plenário do Supremo Tribunal Federal, para dar interpretação conforme à Constituição ao $\S 40$ do art. 11 da Medida Provisória 936/2020, de maneira a assentar que "[os] acordos individuais de redução de jornada de trabalho e de salário ou de suspensão temporária de contrato de trabalho [...] deverão ser comunicados pelos empregadores ao respectivo sindicato laboral, no prazo de até dez dias corridos, contado da data de sua celebração”, para que este, querendo, deflagre a negociação coletiva, importando sua inércia em anuência com o acordado pelas partes. Solicitem-se informações à Presidência da República. Requisitem-se a manifestação do Advogado-Geral da União e o parecer do Procurador-Geral da República. Comunique-se, com urgência. Publique-se. (Ação Direta de Inconstitucionalidade 6363, 2020)"

8 "O Tribunal, por maioria, negou referendo à medida cautelar, indeferindo-a, nos termos do voto do Ministro Alexandre de Moraes, Redator para o acórdão, vencidos 
Ministro Lewandowisk e manter a possibilidade de acordos individuais para a realização de redução de jornada e salário dos empregados, assim como para suspensão dos contratos de trabalho, sem a exigência de ratificação pelos sindicatos.

A Medida Provisória 936 foi, em 6 de julho de 2020, convertida na Lei 14.020, mantendo o Programa Emergencial de Manutenção do Emprego e da Renda e outras medidas complementares para enfrentamento do estado de calamidade pública e da emergência de saúde pública de importância internacional decorrente do coronavírus, de que trata a Lei $n^{0}$ 13.979/2020, trazendo ainda alterações nas Leis $n^{0} 8.213 / 91, n^{0} 10.101 / 00, n^{0}$ $12.546 / 11, \mathrm{n}^{\mathrm{o}} 10.865 / 04$, e 8.177/91.

Quando da conversão em Lei, foram realizados alguns ajustes no texto até então da Medida Provisória, em especial nos artigos $7^{09} \mathrm{e}$ $8^{0_{10}}$, os quais tratam, respectivamente, da redução proporcional da jornada de trabalho e salário dos empregados e da suspensão temporária do contrato de trabalho dos empregados, firmados por convenção ou acordos individual e coletivo.

Marcante também se mostrou a ausência de marcos regulatórios para disciplinar as relações de Direito Privado. Merece destaque, aqui, a Lei 14.010, a qual dispõe sobre o Regime Jurídico Emergencial e Transitório das relações jurídicas de Direito Privado no período da pandemia do coronavírus, mas, apesar disso, foi publicada apenas quatro meses depois da decretação do estado de calamidade

o Ministro Ricardo Lewandowski (Relator), que deferia em parte a cautelar, e os Ministros Edson Fachin e Rosa Weber, que a deferiam integralmente. Ausente, justificadamente, o Ministro Celso de Mello. Presidência do Ministro Dias Toffoli. Plenário, 17.04.2020 (Sessão realizada inteiramente por videoconferência Resolução 672/2020/STF)".

9 “(...) II - pactuação, conforme o disposto nos arts. 11 e 12 desta Lei, por convenção coletiva de trabalho, acordo coletivo de trabalho ou acordo individual escrito entre empregador e empregado". (...) (Lei 14.020/2020).

10 " $\$ 1^{\circ}$ A suspensão temporária do contrato de trabalho será pactuada, conforme o disposto nos arts. 11 e 12 desta Lei, por convenção coletiva de trabalho, acordo coletivo de trabalho ou acordo individual escrito entre empregador e empregado, hipótese em que a proposta de acordo deverá ser encaminhada ao empregado com antecedência de, no mínimo, 2 (dois) dias corridos”. (Lei 14.020/2020). 
pública, ou seja, em 10 de junho de 2020,o que, certamente, refletiu de forma negativa para a sociedade.

Como se não bastasse a tardia publicação, muitas das questões importantes constantes no Projeto de Lei 1.179/2020 apresentado pelo Senado foram vetadas pelo Presidente da República, dentre as quais, as que regulavam questões atinentes à resilição, resolução e revisão de contratos e também acerca da desocupação de imóveis.

Com isso houve um aumento das demandas levadas ao Poder Judiciário que, decidindo de forma urgente para atender aos anseios da sociedade, acabou por proferir decisões com desfechos diversos para mesmas situações, haja vista a ausência de regulação sobre o tema. A exemplo disso, podemos citar decisões proferidas pelos Tribunais tratando da redução ou isenção do pagamento de aluguéis de imóveis comerciais ${ }^{11}$, as quais não mantém um padrão decisório, além de não possuir qualquer embasamento legal específico.

Não há como se negar que foram muitas as medidas adotadas pelo Poder Público, seja no âmbito administrativo, seja no âmbito legislativo. Apesar disso, muitas delas foram tardias, quando não, insuficientes para, de fato, trazer solução aos problemas enfrentados, mantendo-se a insegurança jurídica e deixando clara a necessidade de políticas públicas mais efetivas.

\section{DA MEDIDA PROVISÓRIA no 926/2020 E A AÇÃO DIRETA DE INCONSTITUCIONALIDADE 6341/2020}

Como destacado anteriormente, diversas medidas restritivas foram implementadas no intuito de conter a disseminação da Covid19, assim como a instabilidade social e econômica, sendo também

11 Tribunal de Justiça do Estado de São Paulo. Processo no 102664541.2020.8.26.0100. $22^{\text {a }}$ Vara Cível. São Paulo. 2020; Tribunal de Justiça do Estado de São Paulo. Processo no 1027402-35.2020.8.26.0100. $28^{\text {a }}$ Vara Cível. São Paulo. 2020; Tribunal de Justiça do Estado de São Paulo. Processo no 2069928 09.2020.8.26.0000. $34^{\mathrm{a}}$ Câmara de Direito Privado. São Paulo. 2020. 
apresentadas Medidas Provisórias, Leis, Decretos, Portarias, os quais criaram alguns marcos regulatórios para o cenário apresentado.

Apesar disso, a insegurança jurídica é latente neste momento e inúmeras controvérsias e discussões surgiram em torno das normas editadas, sendo o Supremo Tribunal Federal chamado para se manifestar a fim de solucionar as crises formadas e se manifestar acerca da constitucionalidade das medidas tomadas.

Neste sentido, vale aqui ressaltar o entrave criado em torno da então Medida Provisória $n^{0}$ 926, publicada em 20 de março de 2020, que alterou a Lei $n^{0} 13.979$, de 6 de fevereiro de 2020 - que dispõe sobre as medidas para enfrentamento da emergência de saúde pública de importância internacional decorrente do coronavírus disciplinando acerca dos procedimentos para aquisição de bens, serviços e insumos destinados ao enfrentamento da emergência de saúde pública de importância internacional decorrente do coronavírus (2020), no que tange a competência dos entes federativos.

Referida Medida Provisória trouxe em seu artigo $1^{0}$ a seguinte redação:

A Lei $\mathrm{n}^{0}$ 13.979, de 6 de fevereiro de 2020, passa a vigorar com as seguintes alterações:

Art. $3^{\mathrm{o}}$ Para enfrentamento da emergência de saúde pública de importância internacional decorrente do coronavírus, as autoridades poderão adotar, no âmbito de suas competências, dentre outras, as seguintes medidas: $[\ldots]$

VI - Restrição excepcional e temporária, conforme recomendação técnica e fundamentada da Agência Nacional de Vigilância Sanitária, por rodovias, portos ou aeroportos de:

a) entrada e saída do País; e

b) locomoção interestadual e intermunicipal;

[...]

$\S 8^{\circ}$ As medidas previstas neste artigo, quando adotadas, deverão resguardar o exercício e o funcionamento de serviços públicos e atividades essenciais.

$\S 9^{\circ} \mathrm{O}$ Presidente da República disporá , mediante decreto, sobre os serviços públicos e atividades essenciais a que se referem o $\$ 8^{\circ}$.

$\S 10$. As medidas a que se referem os incisos I, II e VI do caput, quando afetarem a execução de serviços públicos e atividades essenciais, inclusive as reguladas, concedidas ou autorizadas, somente poderão ser adotadas em ato especifico e desde que 
em articulação prévia com o órgão regulador ou o Poder concedente ou autorizador.

$\S$ 11. É vedada a restrição à circulação de trabalhadores que possa afetar o funcionamento de serviços públicos e atividades essenciais, definidas nos termos do disposto no $\S 9^{\circ}$, e cargas de qualquer espécie que possam acarretar desabastecimento de gêneros necessários à população. (grifo nosso)

Com isso, é possível notar que a Medida Provisória nº 926 não apenas trouxe procedimentos para aquisição de bens, serviços e insumos destinados ao enfrentamento da emergência de saúde pública, como também acabou por restringir a competência de Estados, Distrito Federal e Municípios para dispor acerca dos serviços públicos e atividades essenciais, uma vez que atribui competência, para tanto, apenas ao Presidente da República, quando traz que este “disporá, mediante decreto, sobre os serviços públicos e atividades essenciais a que se referem o $\S 8^{\circ}$ " (BRASIL, 2020).

A limitação trazida pela Medida Provisória fez nascer discussão acerca da violação ao princípio federativo e, por consequência, ao artigo 23 da Constituição Federal, uma vez que há restrição à competência comum da União, Estados, Distrito Federal e Municípios para tratar sobre medidas relativas à saúde, isolamento, quarentena, restrição de locomoção por rodovias, portos, aeroportos e interdição de atividades e serviços essenciais.

Assim, com a finalidade de ver declarada a incompatibilidade parcial com a Constituição Federal da Medida Provisória n ${ }^{0}$ 926, relativamente às alterações promovidas no artigo $3^{\mathrm{o}}$ da Lei 13.979/2020 e deste modo sanar controvérsia sobre o tema com declaração expressa do Supremo Tribunal Federal, o Partido Democrático Trabalhista propôs a Ação Direta de Inconstitucionalidade 6341/2020.

O Partido Democrático Trabalhista argumenta em sua inicial que o artigo $1^{\mathrm{o}}$ da Medida Provisória acaba por inovar na Lei Federal $n^{0} 13.979 / 2020$ "quanto a providências de polícia sanitária e aos respectivos legitimados para adotá-las no enfrentamento da emergência de saúde pública de importância internacional decorrente 
do novo coronavírus" (2020, p. 2), havendo importante inconstitucionalidade formal e material na Medida Provisória apresentada.

Continua argumentando que a saúde é matéria reservada pela Constituição à competência comum da União, dos Estados, do Distrito Federal e dos Municípios, conforme disciplina o inciso II do artigo 23 da Constituição Federal de 1988, devendo as normas de cooperação serem fixadas por meio de lei complementar (parágrafo único do artigo 23 da Constituição Federal), descabendo a edição de medida provisória tendo em conta o previsto no artigo 62 , $\S 1^{0}$, da Carta Magna, afirmando que tanto

\begin{abstract}
A medida provisória em tela se imiscuiu no campo reservado à lei complementar - no caso, a cooperação em saúde - que abertamente condicionou a atuação dos demais entes federativos quanto à execução de serviços públicos e atividades essenciais, para que o façam "desde que em articulação prévia com o órgão regulador ou o Poder concedente ou autorizador" (art. $\left.3^{\circ}, \S 10\right)(2020, p$. 7).
\end{abstract}

Houve, portanto, discussão acerca da competência administrativa comum dos entes da federação para tratar da adoção de medidas relativas a saúde, isolamento, quarentena, restrição de locomoção por rodovias, portos e aeroportos e, ainda, interdição de atividades e serviços essenciais tendo em vista a nova redação trazida pela Medida Provisória.

Diante disso, o Partido Democrático Trabalhista requereu, de forma liminar, a declaração de nulidade, por vício formal e material, das alterações trazidas pelo artigo $1^{0}$ da Medida Provisória $\mathrm{n}^{0}$ 926/2020 e, no mérito, a declaração de inconstitucionalidade parcial da MP $n^{0}$ 926/2020, abarcando, por arrastamento, o Decreto 10.282/2020 (2020), versando, portanto, a discussão constante na Ação Direta de Inconstitucionalidade 6341 a respeito de providências de polícia sanitária e acerca de quais são os legitimados para adotá-las neste presente momento de emergência de saúde pública.

Assim, levou-se ao Poder Judiciário o encargo de interpretar as diretrizes trazidas pela Medida Provisória $n .^{\circ}$ 926, de modo a 
declarar se ela está alinhada com os ditames constitucionais e, deste modo, decidir acerca de sua constitucionalidade para que os entes federativos façam jus à competência a eles atribuída por meio da Constituição Federal de 1988 e decidam acerca das medidas constantes da Lei 13.979/2020.

Destarte, tendo em vista a relevância e urgência envolvendo o tema, o Ministro Marco Aurélio apreciou, de forma monocrática, os pedidos constantes na medida cautelar, tendo deferido parte da demanda pleiteada, entendendo pela existência de competência concorrente dos entes federativos para a adoção de medidas sanitárias de combate à crise decorrente do coronavírus:

\begin{abstract}
Vê-se que a medida provisória, ante quadro revelador de urgência e necessidade de disciplina, foi editada com a finalidade de mitigar-se a crise internacional que chegou ao Brasil, muito embora no território brasileiro ainda esteja, segundo alguns técnicos, embrionária. Há de ter-se a visão voltada ao coletivo, ou seja, à saúde pública, mostrando-se interessados todos os cidadãos. $\mathrm{O}$ artigo $3^{\circ}$, cabeça, remete às atribuições, das autoridades, quanto às medidas a serem implementadas. Não se pode ver transgressão a preceito da Constituição Federal. As providências não afastam atos a serem praticados por Estado, o Distrito Federal e Município considerada a competência concorrente na forma do artigo 23, inciso II, da Lei Maior (2020, p. 6).
\end{abstract}

Com isso, firmou o Ministro Marco Aurélio entendimento de que a disciplina decorrente da Medida Provisória $n^{\circ}$ 926/2020, no que imprimiu nova redação ao artigo $3^{\circ}$ da Lei 13.979/2020, não afastou a tomada de providências normativas e administrativas pelos Estados, Distrito Federal e Municípios, deferindo, "em parte, a medida acauteladora, para tornar explícita, no campo pedagógico e na dicção do Supremo, a competência concorrente" (2020, p. 6).

Nota-se que o Ministro Marco Aurélio reconheceu a competência concorrente dos entes da federação para cuidar de assuntos relacionados à saúde, de forma diversa da expressa no artigo 23 da Constituição Federal.

Como se sabe, o modelo constitucional atualmente existente encampou modelo federalista baseado num complexo sistema de repartição de competências, reunindo critérios de ótica horizontal e 
vertical para a partilha de competências entre a União, Estados, Distrito Federal e Municípios. Contemplou ainda competências comuns e hipóteses de delegação de competências da União para os Estados membros, com fundamento ideológico no federalismo de equilíbrio (GONZALES, 2011).

Como destaca Gonzales, a competência concorrente constitui apurada técnica do federalismo de equilíbrio,

Diante da parceria de ação e responsabilidade que se estabelece entre os entes federados para a consecução de objetivos comuns e do regramento conjunto dos assuntos que extravasam o interesse de um único ente político. Cuida-se, pois, de mecanismo de descentralização política e de encargos administrativos, dada a peculiaridade de cada ente federado disciplinar determinado assunto fiel às suas peculiaridades, rumo a um progresso conjunto e planejado de toda a nação. (2011, p. 43)

Ocorre que no presente caso, a matéria a ser discutida referese à saúde e, como se observa com a leitura do artigo 23 da Constituição, está expressamente disciplinada em seu inciso II a competência comum aos entes da federação para tratar sobre o tema:

Art. 23. É competência comum da União, dos Estados, do Distrito Federal e dos Municípios:

[...]

II - Cuidar da saúde e assistência pública, da proteção e garantia das pessoas portadoras de deficiência; [...] (grifo nosso)

E ainda, completou o ministro sua decisão manifestando-se que não há reserva para lei complementar disciplinar sobre a matéria em discussão, afirmando que

Descabe a ótica no sentido de o tema somente poder ser objeto de abordagem e disciplina mediante lei de envergadura maior. Presentes urgência e necessidade de ter-se disciplina geral de abrangência nacional, há de concluir-se que, a tempo e modo, atuou o Presidente da República - Jair Bolsonaro - ao editar a Medida Provisória. O que nela se contém - repita-se à exaustão não afasta a competência concorrente, em termos de saúde, dos Estados e Municípios. (2020, p. 5)

Ao contrário disso, o parágrafo único do artigo 23 da Constituição Federal dita que as "leis complementares fixarão normas 
para a cooperação entre a União e os Estados, o Distrito Federal e os Municípios, tendo em vista o equilíbrio do desenvolvimento e do bemestar em âmbito nacional" (1988).

Neste sentido, Gonzales traz que a cooperação, assim como o regime de atuação dos entes federativos no que diz respeito a competência comum

Será orquestrada por meio de leis complementares federais de eficácia nacional (EC no 52), tendo em vista o equilíbrio de desenvolvimento e o bem-estar nacional, consoante dispõe o artigo 23 em seu parágrafo único. Logo, caberá ao ente central ditar o regime de execução das áreas de competência comum. Enquanto ausente tal normativa, cada ente federativo é autônomo para expressar-se ao seu alvedrio e conveniência, mas sempre visando o bem-estar nacional, objetivo maior de nossa República Federal (art. 30, II, da CF). (GONZALES, 2011, p. 45)

Assim, a cooperação é elemento central "que gravita todas as engrenagens de competências e atribuições dos entes federados" (GONZALES, 2011, p. 73). Valendo ressaltar que a "coordenação está para as competências legislativas concorrentes; assim como a cooperação está para as competências comuns” (GONZALES, 2011, p. 73).

Levada a Plenário a decisão proferida pelo relator em cautelar, entenderam os ministros do Supremo Tribunal Federal, por maioria, em 15 de abril de 2020, por referendar

A medida cautelar deferida pelo Ministro Marco Aurélio (Relator), acrescida de interpretação conforme à Constituição ao $\S 9^{\circ}$ do art. $3^{\circ}$ da Lei ${ }^{\circ} 13.979$, a fim de explicitar que, preservada a atribuição de cada esfera de governo, nos termos do inciso I do art. 198 da Constituição, o Presidente da República poderá dispor, mediante decreto, sobre os serviços públicos e atividades essenciais vencidos, neste ponto, o Ministro Relator e o Ministro Dias Toffoli (Presidente), e, em parte, quanto à interpretação conforme à letra $\mathrm{b}$ do inciso VI do art. $3^{\circ}$, os Ministros Alexandre de Moraes e Luiz Fux. (...) (Sessão realizada inteiramente por videoconferência, em 15.04.2020 - Resolução 672/2020/STF).

Apesar do Supremo Tribunal Federal ter mantido a redação original proposta na Medida Provisória, a decisão é parcialmente procedente no que tange à interpretação dada à norma, não 
reconhecendo a possibilidade de se atribuir competência exclusiva ao Presidente da República para tratar da matéria.

Nos dizeres do Ministro Gilmar Mendes (2020, p. 12), quando da apresentação de seu voto, ele ressalta a existência de um conflito aparente de normas constitucionais, uma vez que

$\mathrm{O}$ art. 21, XVIII, da Constituição estabelece ser competência da União planejar e promover a defesa permanente contra as calamidades públicas, especialmente as secas e as inundações; ao passo que o art. 23, II, dispõe ser competência comum da União, Estados, Distrito Federal e Municípios cuidar da saúde e assistência públicas. Ademais, o art. 22, X e XI, determina ser competência privativa da União legislar sobre trânsito e transporte, bem como sobre o regime dos portos, navegação lacustre, fluvial, marítima, aérea e aeroespacial; enquanto o art. 24, XII, estatui a competência concorrente da União, dos Estados e do Distrito Federal para editar normas sobre previdência social, proteção e defesa da saúde. O art. 30, I, ainda dispõe ser competência dos Municípios legislar sobre assuntos de interesse local.

Assim dada a complexidade no que tange à matéria aqui discutida, sendo facilmente identificável um conflito aparente de normas, acaba a União por se apegar a dispositivos constitucionais relativos à sua competência exclusiva e os demais entes federativos invocam a existência da competência comum entre eles (MENDES, 2020).

Apesar disso, o ministro defende que "independentemente do direcionamento da política pública de saúde que se pretenda adotar, é inviável que ela seja executada sem uma articulação mínima com os Estados e Municípios" (MENDES, 2020, p. 13), devendo se atentar para a necessidade de cooperação entre os entes federativos.

Conforme traz Gonzales, a ideia de divisão vertical de competências legislativas

Só surge efetivamente com a eclosão do fenômeno político, histórico e jurídico do federalismo, pois antes se trabalhava ora com meras divisões administrativas, ora com a ideia de alianças e de pactos, onde não se estabelecia vínculos duradouros ou seguros o suficiente para assegurar a autonomia dos entes partes. (GONZALES, 2011, p. 4). 
É apenas com o surgimento do Federalismo que se passa a visualizar a divisão jurídica "da repartição de competências administrativas e legiferantes ao longo do território do Estado, fundada na mais complexa estrutura governamental então conhecida. Cuida-se, pois, de fenômeno histórico, político e jurídico a criação do Estado Federal" (GONZALES, 2011, p. 5).

Cabe aqui também citar que Lowenstein (1986, p. 353) trata o Federalismo como sendo o enfrentamento entre duas soberanias estatais diferentes, separadas territorialmente e que se equilibram mutuamente. A existência de fronteiras federais limita o poder do Estado central e sobre o Estado membro e vice-versa" (tradução nossa) ${ }^{12}$. É para ele, portanto, o Federalismo, uma forma de divisão espacial, existindo, porém, um controle vertical do Poder Público.

$\mathrm{O}$ federalismo cooperativo tem por fundamento a cooperação mútua entre os entes federados para que assim as tarefas de interesse comum sejam melhores desempenhadas "através de um entrelaçamento e interdependência entre os níveis de governo em prol do interesse do cidadão e do equilíbrio de forças da Federação" (GONZALES, 2011, p. 72).

Neste sentido, em seu voto, o Ministro Fachin, traz que "a delegação de competência a um dos poderes do Estado não pode implicar, sob o ângulo material, a hierarquização dos poderes ou das esferas de Governo" (FACHIN, 2020, p. 20), e assim, decidiu por conceder parcialmente a cautelar dando interpretação conforme à Constituição ao $\S 9^{\circ}$ do art. $3^{\circ}$ da Lei 13.979 , ressaltando que, "preservada a atribuição de cada esfera de governo, nos termos do inciso I do artigo 198 da Constituição, o Presidente da República poderá dispor, mediante decreto, sobre os serviços públicos e atividades essenciais" (FACHIN, 2020, p. 20).

${ }_{12}$ Texto original: "El federalismo: el enfrantamiento entre dos soberanías diferentes estatales separadas territoriamente y que se equilibran mutuamente. La existência de fronteras federales limita el poder del Estado central sobre el Estado miembro, y la inversa." 
Assim, a resposta proferida pelo Supremo Tribunal Federal teve o condão, não de interferir na atividade do Poder Executivo fomentando o embate político, mas sim de viabilizar as decisões do governo, dando efetividade e o correto direcionamento a estas, respeitando a competência atribuída pela Constituição a cada um dos Poderes.

Evidencia-se, assim, uma iniciativa por parte do Poder Judiciário de realizar um diálogo institucional, com respeito à separação dos poderes e aos ditames constitucionais, o que demonstra ser a melhor forma para a resolução das discussões trazidas a juízo, como será melhor discutido adiante em tópico próprio.

Como traz Fachin em seu voto:

O papel do Supremo Tribunal Federal nos conflitos federativos deve ser o de abster-se de declarar a inconstitucionalidade formal à míngua de legislação federal editada de forma nítida e precisa. O locus da atuação concentrada da Corte muda, consequentemente, de foco, para minuciosamente examinar as ofensas materiais à Constituição. Afinal, mais relevante do que saber quem é o ente competente para lidar com a emergência sanitária é saber como União, Estados e Municípios devem agir (FACHIN, 2020, p. 11).

O Supremo, portanto, ao decidir sobre a constitucionalidade da Medida Provisória $n^{0}$ 926/2020, optou pela decisão menos gravosa, dando interpretação conforme a Constituição, reconhecendo a competência comum da União, dos Estados, do Distrito Federal e dos Municípios, para tratar dos pontos objeto da presente discussão.

Ocorre que a Medida Provisória 926 foi convertida na Lei 14.035, de 11 de agosto de 2020, sendo aprovadas alterações na redação originalmente trazida pela Medida, em especial ao $\S 9^{\circ}$, o qual passou a disciplinar que "a adoção das medidas previstas neste artigo deverá resguardar o abastecimento de produtos e o exercício e o funcionamento de serviços públicos e de atividades essenciais, assim definidos em decreto da respectiva autoridade federativa”, não mais fazendo menção à competência exclusiva do Presidente para dispor acerca dos serviços públicos e atividades essenciais. 


\section{DO CONTROLE DE CONSTITUCIONALIDADE E DA NECESSIDADE DOS DIÁLOGOS INSTITUCIONAIS}

O recorrente acesso ao Poder Judiciário, seja no âmbito de primeiro grau com o aumento da judicialização de questões cotidianas, ou então no âmbito dos tribunais com a necessidade recorrente de declaração, pelo Supremo Tribunal Federal, de (in)constitucionalidade das leis e medidas criadas pelos Poderes Legislativo e Judiciário, fez aumentar a atividade judicial e, por consequência, exaltar o protagonismo do Poder Judiciário.

Especificamente no que tange ao controle judicial de constitucionalidade realizado pelo Supremo Tribunal Federal, cumpre mencionar que este nasceu em um ambiente jurídico de tradição do common law, "na qual os juízes têm por dever dizer o que é o direito, por intermédio de uma razão artificial que adquirem mediante horas de estudo disciplinado, somadas à observância e à experiência prática na lide jurídica" (VICTOR, 2015, p. 96).

Assim, o sistema acaba por admitir, portanto, que juízes (não eleitos pelo povo) invalidem leis criadas pelos demais Poderes (formados por membros eleitos pelo povo), quando as declaram inconstitucionais.

Discute-se, portanto, na doutrina, o caráter contramajoritário das decisões proferidas por meio do controle de constitucionalidade (judicial review). Nos dizeres de Bickel (1986, p. 16), quando a Corte declara a inconstitucionalidade de uma lei ela acaba por "exercer um controle, não em favor da maioria predominante, mas contra ela" (tradução nossa) ${ }^{13}$.

Apesar disso, não se admite que o controle judicial de constitucionalidade seja realizado de forma discricionária ou para atender anseios pessoais e políticos. O Judiciário deve fazer a

${ }_{13}^{13}$ Texto original: "exercises control, not in behalf of the prevailing majority, but against it” (BICKEL, 1986, p. 16). 
interpretação da norma, de modo a verificar se esta atende aos preceitos constitucionais postos.

Como mencionado anteriormente, as medidas provisórias analisadas no presente trabalho foram submetidas ao controle de constitucionalidade por meio das Ações Diretas de Inconstitucionalidade 6341, 6342, 6343 e 6363/2020. Mereceu destaque, portanto, sem qualquer demérito às demais decisões, a forma com que o Supremo Tribunal Federal se manifestou quando da análise da constitucionalidade da Medida Provisória no 926, uma vez que referida Medida apresentou alteração no artigo $3^{\circ}$ da Lei 13.979/2020, limitando a competência dos Estados, Distrito Federal e Municípios.

O Supremo Tribunal Federal deu parcial provimento à ação proposta, decidindo pela interpretação conforme à Constituição ao § $9^{\circ}$ do art. $3^{\circ}$ da Lei ${ }^{\circ} 13.979$, declarando que, "preservada a atribuição de cada esfera de governo, nos termos do inciso I do art. 198 da Constituição, o Presidente da República poderá dispor, mediante decreto, sobre os serviços públicos e atividades essenciais”.

Assim, o Tribunal manteve a redação dada pela Medida Provisória ao artigo $3^{\circ}$ da Lei 13.979/2020, mas atribuiu aos demais entes da federação a competência que lhes é cabível, retirando, portanto, a limitação trazida pela Medida Provisória ao artigo $3^{\circ}$ da Lei.

Como mencionado anteriormente, o Tribunal poderia, haja vista atribuição que lhe é conferida, declarar a inconstitucionalidade da medida em discussão, mas, ao contrário disso, decidiu por manter a redação posta, mas aplicar interpretação adequada aos ditames constitucionais, de modo que qualquer interpretação que seja dada à norma no sentido de garantir exclusividade ao Presidente da República para tratar sobre o tema, será declarada inconstitucional.

Evitou assim, o Supremo Tribunal Federal, que as discussões acerca do tema se acirrassem e preferiu, ao invés do embate, o diálogo 
institucional como medida de maior eficiência, com a prática das "virtudes passivas" de Bickel.

Victor (2015, p. 105) explicando a prática das "virtudes passivas de Bickel traz que

Os juízes devem ser bastante deferentes às razões elaboradas por membros dos outros Poderes e, assim, serão mais pacientes, cuidadosos e tolerantes no exercício do controle judicial de constitucionalidade. Significa dizer que os juízes da Suprema Corte, em especial, devem considerar, com respeito e compreensão, os pontos de vista das demais partes e autoridades, de forma que possam perceber a profunda complexidade dos assuntos públicos que lhes são submetidos e, portanto, ser relutantes e cuidadosos no que diz respeito à sua própria intervenção.

Com a aplicação das "virtudes passivas" de Bickel, as decisões passariam a ser mais prudentes e minimizariam as discussões entre os Poderes, tornando os diálogos entre as instituições mais sólidos e despidos de interesses pessoais, políticos ou midiáticos. A decisões passam a ser mais contidas e focadas na matéria objeto da divergência.

As decisões das Cortes, por meio da prática das "virtudes passivas", perdem seu caráter autoritário e são capazes de atingir de forma mais igualitária a todos. Passam a ser decisões mais seguras, uma vez que favorecem o diálogo institucional estimulando o debate público.

Nos dizeres de Cléve e Lorenzetto a prática dos diálogos institucionais

Procura evidenciar pelo menos dois aspectos a respeito da formulação de decisões de casos controvertidos. Primeiro, as decisões, tomadas em qualquer um dos poderes, passam a ter um caráter parcialmente definitivo, pois, podem ser contestadas em outras instâncias públicas. Segundo cada espaço de poder possui características que o potencializam ou o inibem para a realização de tomada de decisões. Isso reafirma a necessidade de canais de diálogo entre as instituições, pois, uma pode ter melhores condições que outra para lidar com o caso concreto em apreço. (CLÉVE e LORENZETTO, 2015, 189).

Vale também citar que o Ministro Gilmar Mendes, quando da redação de seu voto, cita que o SUS (Sistema único de Saúde) "é a materialização mais clara do regime de federalismo cooperativo" (2020, p. 23). Sendo a previsão normativa da Comissão Intergestores 
Tripartite (CIT) relevante inovação gerencial na política pública de saúde no Brasil, pois

Trata-se de foros permanentes de negociação, articulação e decisão entre os gestores nos aspectos operacionais e na construção de pactos nacionais, estaduais e regionais no Sistema Único de Saúde (SUS), para que haja o fortalecimento da governança nesses espaços. Além disso, a Comissão prioriza a responsabilização dos entes, de modo que a tomada de decisão na gestão tenha transparência (2020, p. 23).

Medidas de cooperação como estas faz com que as necessidades de Municípios e Estados sejam atendidas de forma particular. O Brasil é um país de dimensão continental, o que torna as necessidades de municípios e Estados das mais variadas.

Deste modo, o diálogo entre os entes relacionados à matéria em discussão se fortalece e a regionalização das medidas, com a atribuição de competência a Estados e Municípios, também faz com que as medidas adotadas em prol da sociedade sejam ainda mais concretas, uma vez que as necessidades de cada região, dada a grande dimensão do Brasil, são muito diferentes.

\section{CONSIDERAÇÕES FINAIS}

Atualmente, estamos vivendo em um momento atípico, em que o caos foi instalado devido ao Covid-19 que, a cada dia, faz com que o número de mortes aumente. Com isso, a necessidade de disciplinar as novas situações e trazer, ainda que minimamente, segurança jurídica para as relações, fez com que inúmeras medidas fossem criadas.

Os Poderes Legislativos e Executivos criaram medidas restritivas de circulação e também medidas para regular as relações de trabalho, econômicas e civis. A urgência requerida para a criação destas normas, assim como a ausência de precedentes concretos para servir de paradigma ao que se propôs, fez com que muitas destas medidas fossem envolvidas em vícios formais e materiais, quando não, 
insuficientes para regular o atual cenário, sendo alvo de muitas críticas.

Observou-se um aumento da judicialização, assim como do protagonismo do Poder Judiciário, sendo o Supremo Tribunal Federal, por inúmeras vezes, chamado por meio de Ações Diretas de Inconstitucionalidade para se manifestar.

Foram muitas as ações propostas, sendo no presente trabalho, de forma breve, destacada as decorrentes da Lei 14.010/2020, assim como as que vieram questionar as Medidas Provisórias $\mathrm{n}^{0} 927$ e $\mathrm{n}^{0}$ 936/2020 e, de forma um pouco mais detalhada a Medida Provisória $\mathrm{n}^{0} 926$.

Nota-se, portanto, a necessidade de diálogo entre as instituições para que a norma possa ser revestida de constitucionalidade e, também, para que direitos e deveres possam ser entregues para a sociedade de forma mais efetiva, de modo a gerar maior segurança jurídica.

O Poder Judiciário, ao contrário do que por muitas vezes se propala, acaba por viabilizar as medidas tomadas pelos demais Poderes, à medida que profere decisões concretas, em conformidade com os ditames constitucionais; tais decisões, a nosso ver, não tem como objetivo fomentar a discussão entre os Poderes, mas sim, cumprir as prescrições da Constituição Federal.

Assim, os Poderes devem, de forma harmônica, dialogar acerca da correta aplicabilidade da norma, de modo a garantir que a sociedade tenha seus anseios atendidos e as regras constantes na Constituição Federal sejam respeitadas, evitando-se, deste modo, a disputa pelo poder da última palavra.

Data de Submissão: 30/07/2020

Data de Aprovação: 17/19/2020

Processo de Avaliação: double blind peer review

Editor Geral: Jailton Macena de Araújo 
O Protagonismo Do Poder Judiciário Ante A Necessidade Recorrente Do...

Editor de Área: Jailton Macena de Araújo

Assistente Editorial: Thaynná Batista de Almeida

\section{REFERÊNCIAS}

BARROSO, Luís Roberto. Constituição, democracia e supremacia judicial: direito e política no Brasil contemporâneo. Revista da

Faculdade de Direito - UERJ, v. 12, n. 21, jan. /jun. 2012.

Disponível em: https://www.e-

publicacoes.uerj.br/index.php/rfduerj/article/view/1794. Acesso em: 6 ago. 2020.

BICKEL, Alexander M. The least dangerous branch: the

Supreme Court at the bar of politics.2. ed. With a new foreword by Harry H. Wellington. New Haven and London: Yale University Press, 1986, p. 16-17.

BRASIL. Constituição da República Federativa do Brasil de 1988. Brasília, DF. Disponível em:

http://www.planalto.gov.br/ccivil_03/constituicao/constituicao.htm . Acesso em 14 jul 2020.

BRASIL. Decreto Legislativo no 6, de 20 de março de 2020. Brasília, DF. Disponível em:

http://www.planalto.gov.br/ccivil_03/portaria/DLG6-2020.htm. Acesso em: 14 jul 2020.

BRASIL. Lei 13.979, de 6 de fevereiro de 2020. Brasília, DF. Disponível em http://www.planalto.gov.br/ccivil_03/_ato20192022/2020/lei/l13979.htm. Acesso em 14 jul 2020.

BRASIL. Lei14.010, de 10 de junho de 2020. Brasília, DF. Disponível em https://legislacao.presidencia.gov.br/ficha?/legisla/legislacao.nsf/Vi w_Identificacao/lei\%2014.010-2020\&OpenDocument. Acesso em 14 jul 2020.

BRASIL. Medida Provisória no 926, de 20 de março de 2020. Brasília, DF. Disponível em: http://www.planalto.gov.br/ccivil_03/_ato20192022/2020/Mpv/mpv926.htm. Acesso em: 20 jul 2020.

BRASIL. Medida Provisória no 927 , de 22 de mar de 2020. Brasília, DF. Disponível em: http://www.planalto.gov.br/ccivil_03/_ato20192022/2020/Mpv/mpv927.htm. Acesso em: 20jul 2020.

BRASIL. Medida Provisória no 936, de $1^{\circ}$ de abril de 2020. Brasília, DF. Disponível em: 
http://www.planalto.gov.br/ccivil_03/_Ato2019-

2022/2020/Mpv/mpv936.htm. Acesso em: 20jul 2020.

BRASIL. Supremo Tribunal Federal. Ação Direta de

Inconstitucionalidade $n^{0}$ 6341. Relator: MARCO AURÉLIO.

Brasília, DF, 24 de março de 2020. Disponível em:

http://portal.stf.jus.br/processos/detalhe.asp?incidente $=5880765$.

Acesso em 20 jul 2020.

BRASIL. Supremo Tribunal Federal. Ação Direta de

Inconstitucionalidade $\mathbf{n}^{\circ}$ 6341. Relator: MARCO AURÉLIO.

Brasília, DF, 15 de abril de 2020. Disponível em

https://www.conjur.com.br/dl/voto-gm-competencia-

concorrente.pdf. Acesso em 20 jul 2020.

BRASIL. Supremo Tribunal Federal. Ação Direta de

Inconstitucionalidade no 6341. Relator: MARCO AURÉLIO.

Brasília, DF, 15 de abril de 2020. Disponível em

https://www.conjur.com.br/dl/voto-edson-fachin-acoes-

competencia.pdf. Acesso em 20 jul 2020.

BRASIL. Supremo Tribunal Federal. Ação Direta de

Inconstitucionalidade n⿳ 6342. Relator: MARCO AURÉLIO. Brasília, DF, 26 de março de 2020. Disponível em:

http://www.stf.jus.br/arquivo/cms/noticiaNoticiaStf/anexo/ADI634 2liminar.pdf. Acesso em 20 jul 2020.

BRASIL. Supremo Tribunal Federal. Ação Direta de

Inconstitucionalidade no 6343. Relator: MARCO AURÉLIO. Brasília, DF, 26 de março de 2020. Disponível em:

http://portal.stf.jus.br/processos/detalhe.asp?incidente $=5881008$.

Acesso em 20 jul 2020.

BRASIL. Supremo Tribunal Federal. Decisão em Medida

Cautelar no 6363. Relator: RICARDO LEWANDOWSKI. Brasília, DF, 6 de abril de 2020. Disponível em:

http://redir.stf.jus.br/paginadorpub/paginador.jsp?docTP=TP\&docI $\mathrm{D}=752428536 \& \mathrm{prcID}=5886604 \& \mathrm{ad}=\mathrm{s} \#$. Acesso em: 20 jul 2020.

BRASIL. Supremo Tribunal Federal. Decisão em Medida

Cautelar no 6363. Relator: RICARDO LEWANDOWSKI. Brasília, DF, 17 de abril de 2020. Disponível em:

http://redir.stf.jus.br/estfvisualizadorpub/jsp/consultarprocessoelet ronico/ConsultarProcessoEletronico.jsf?seqobjetoincidente $=588660$ 4. Acesso em: 20 jul 2020.

CLÈVE, Clèmerson Merlin; LORENZETTO, Bruno Meneses. Diálogos institucionais: estrutura e legitimidade. Revista de Investigações

Constitucionais, Curitiba, vol. 2, n.3, p. 183-206, set. /dez.2015.

Disponível em: https://www.scielo.br/scielo.php?pid=S2359-

56392015000300183\&script=sci_arttext. Acesso em: 20 ago. 2020. 
O Protagonismo Do Poder Judiciário Ante A Necessidade Recorrente Do...

Germany. Março, 2020. Disponível em

https://verfassungsblog.de/fighting-covid-19-legal-powers-andrisks-germany/. Acesso em 17 jul 2020.

GONZALES, Douglas Camarinha. Competência Legislativa dos Entes Federados: conflitos e interpretação constitucional. 2011. Disponível em https://www.teses.usp.br/teses/disponiveis/2/2134/tde-16082012150740/publico/DOUGLAS_CAMARINHA_GONZALES_COMPLET A_CONFERIDA.pdf. Acesso em 17 jul 2020.

KLAFKI, Anika; KIEßLING, Andrea. Fighting COVID 19 - Legal Powers and Risks:

LOEWENSTEIN, Karl. Teoria de la Constituición. Barcelona.Ed. Ariel S/A, 1986, p. 353 .

MANDARINO, Renan Posella; FREITAS, Marisa Helena D'Arbo Alves de. Ativismo judicial e judicialização da política da relação de consumo: uma análise do controle jurisdicional dos contratos de planos de saúde privado no estado de São Paulo. Revista

Brasileira de Políticas Públicas, Brasília, v. 5, n. especial, 2015 p. 347-360.

OPAS-Brasil. Organização Pan-Americana da Saúde. Folha informativa - COVID-19 (doença causada pelo novo coronavírus). 2020. Disponível em:

https://www.paho.org/bra/index.php?option=com_content\&view=a rticle\&id=6101:covid19\&Itemid=875. Acesso em 18 jul 2020.

STRECK, Lenio Luiz. Verdade e consenso. Constituição hermenêutica e teorias discursivas. 4. ed. São Paulo: Saraiva, 2011, p. 589, nota de rodapé 123 .

VEIGA, Aloysio Corrêa da; SIVOLELLA, Roberta Ferme. Dejà-vu Histórico, Normatividade e Sociedade em Mutação: o direito em quarentena nas medidas de prevenção contra o covid-19. O Direito do Trabalho na crise da COVID-19/ coordenadores Alexandre Angra Belmonte, Luciano Martinez, Ney Maranhão. Salvador: Editora JusPodivm, 2020.

VICTOR, Sérgio Antônio Ferreira. Diálogo institucional e controle de constitucionalidade: debate entre o STF e o Congresso Nacional. São Paulo: Saraiva, 2015.

WORLD HEALTH ORGANIZATION. Coronavirus disease(COVID-19) Pandemic. 2020. Disponível em: https://www.who.int/emergencies/diseases/novel-coronavirus2019. Acesso em: 19 jul 2020. 


\title{
The Protagonism Of The Judicial Branchin Front Off The Recurrent Need For The Judicial Control of Constitutionality Of The New Provisional Measures
}

\author{
Angela Soncin
}

Juvêncio Borges Silva

\begin{abstract}
This present article aims to highlight that the urgency for regulatory frameworks that discipline situations that have never been experienced, such as those currently generated by the state of calamity decreed as a result of the coronavirus (COVID-19), caused the Judiciary to be exhaustively provoked to manifest, which ended up generating discussion about the advance of the protagonism of this Power in view of the measures adopted by the Executive and Legislative Powers.The present research is justified since the Judicial Branch has exercised considerable leadership in the social and political arena, with decisions that have had repercussions on these spheres. It is an exploratory, qualitative research, which uses the analytical-deductive method, and which uses books, scientific articles and doctrinal texts.The research shows that, despite the protagonism of the Judiciary, it does not act in a way to create a clash between the Powers, but that, through the existence of institutional dialogues, it is possible to guarantee the prevalence of the Federal Constitution over political interests, without interfere in the competence of the other Powers.
\end{abstract}

Keywords: Regulatory Frameworks. Protagonism. Institutional Dialogues. Judicial Branch. 